
Movement of a Solute in

the Potomac River Estuary

at Washington, D.C.

at Low Inflow Conditions

By James F. Wilson, Jr., Ernest D. Cobb, and

Nobuhiro Yotsukura

P O TOMACR I V ER S T U D I E S

GEOLOGICAL SURVEY CIRCULAR $529-B$

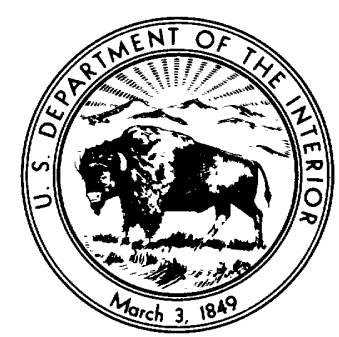


United States Department of the Interior WALTER J. HICKEL, Secretary

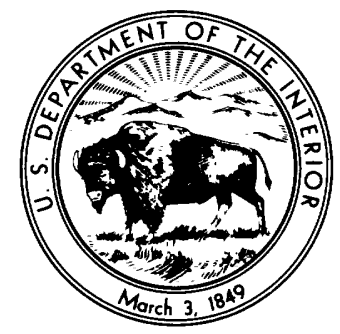

Geological Survey

William T. Pecora, Director

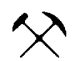

Free on application to the U.S. Geological Survey, Washington, D.C. 20242 


\section{CONTENTS}

Page

Abstract............. 1

Introduction........ 1

Acknowledgments.................. 1

Description of the study reach _......- 1

Field procedures . . . 3

Presentation of data .............. 3

Dye-distribution maps _........... 3

Aerial photographs........ 8

Presentation of data-Continued

Page

Stage and discharge records........ 8

Average movement of dye mass...... 9

Observed movement ............. 9

Estimated movement ............. 10

Characteristics of dispersion.-...-. $\quad 12$

Summary and conclusions . . . . . . . . 14

References....................... 14

\section{ILLUSTRATIONS}

Page

Plate 1. Maps showing movement of soluble dye in the Potomac River estuary------In pocket

Figure 1. Map showing location of study reach..

2. Diagrammatic sketch of fluorometer hookup in sampling boat

3. Graph showing attenuation of peak concentration with time

4-6. Aerial photographs of:

4. Dye cloud 1.9 hours after dye injection

5. Dye cloud 4.4 hours after dye injection

6. Dye cloud 6.7 hours after dye injection

7-12. Graphs showing:

7. Potomac River estuary water-surface elevations at GSA wharf, Alexandria, Va _....... 8

8. Nontidal discharge flowing into the Potomac River estuary - .

9. Distribution of dye mass in the longitudinal direction

10. Observed and estimated movement of dye-mass centroid with time...... 11

11. Increase of variance and length of dye cloud with time

12. Attenuation of peak dye mass with time

TABLES

1. Computed recovery of the total dye mass at various stages of dilution.

2. Product of peak dye mass, $M_{p}^{\prime}$, and dye cloud length, $L$, at various stages of dilution 
SYMBOLS

A Cross-sectional area of estuary

$C_{p}$ Observed peak dye concentration

$i$ Cross-section number

$L \quad$ Dye-cloud length along the estuary

$N$ Total number of cross sections

$M_{i}$ Mass of dye per unit length of estuary

$M_{i}^{\prime}$ Mass of dye per unit length of estuary adjusted for dye loss

$M_{p}$ Peak of the dye-mass distribution

$M{ }_{p}^{\prime}$ 'Peak of the dye-mass distribution adjusted for dye loss

$Q_{I}$ Total upstream inflow to the estuary

$Q_{O}$ Total discharge through a selected estuary cross section

$\Delta S$ Change in storage above a selected estuary cross section $t$ Time

$\Delta t \quad$ Increment of time

$V^{\prime} \quad$ Average tidal velocity

$\bar{X} \quad$ Location of dye-mass centroid measured from the release point along the estuary centerline

$\triangle X \quad$ Increment of longitudinal distance

$X_{i} \quad$ Distance measured along the estuary centerline from the release point

$\Delta X_{i} \quad$ Subreach length

$\Sigma \quad$ Summation

$\sigma_{x}$ Standard deviation, in the longitudinal direction, of the dye-mass distribution 


\title{
Movement of a Solute in the Potomac River Estuary at Washington, D. C., at Low Inflow Conditions
}

\author{
By James F. Wilson, Jr., Ernest D. Cobb, and Nobuhiro Yotsukura
}

\section{ABSTRACT}

The movement of a solute, as represented by a soluble fluorescent dye, was observed in the Potomac River estuary at Washington, D.C. The average net rate of downstream movement of the solute centroid was less than 0.6 mile per day. The movement of a solute is highly dependent on the nontidal inflow to the estuary. During the study, the average inflow was 900 cubic feet per seconda very low value, equaled or exceeded 98 percent of the time. Using a storage equation, the average movement of a solute was estimated for nontidal inflow of 3,100 and 6,500 cubic feet per second; these inflows are equaled or exceeded 75 and 50 percent of the time, respectively.

The study showed that tidal action was fairly efficient in dispersing the solute longitudinally. The solute, which was dumped 1,000 feet upstream from the 14th Street Bridge, was observed as far upstream as Roosevelt Island. A transient longitudinal dispersion coefficient at the end of 150 hours was determined to be 210 square feet per second. On the other hand, the lateral diffusion was a slow process and the lateral distribution of the solute was far from uniform at the end of $6 \frac{1}{2}$ days after the release.

\section{INTRODUCTION}

The purpose of this report is to describe the movement of a soluble material in the Potomac River estuary at Washington, D.C.

In 1964 , a time-of-travel study of a solute was made by the U.S. Geological Survey in the Potomac River from Cumberland, Md., to the upper end of the Potomac River estuary at Chain Bridge in Washington, D.C. (Wilson and Forrest, 1965). The Federal Water Pollution Control Administration in 1965 made a study of the movement and dispersion of a solute in the Potomac River estuary downstream from Washington, D.C. (Hetling and O'Connell, 1966). The study reported herein is for a part of the estuary lying between these two study areas.

\section{ACKNOWLEDGMENTS}

The aerial photographs used in this report were provided by the U.S. Geological Survey project office, Phoenix, Ariz. The authors especially appreciate the help of M.A.Keenan, engineering aid, who reduced the basic data.

\section{DESCRIPTION OF THE STUDY REACH}

The physical characteristics of the study reach are well summarized by Durum and Langbein (1966, p. 1) as follows:

"The tide in the Potomac River reaches just above Chain Bridge near the western limit of the District of Columbia. There is sharp contrast between the swift, turbulent, narrow river seen looking upstream from Chain Bridge and the gentle currents of the wide estuary just downstream at Georgetown. The quality of water in the estuary is, a composite of the effects of the tide, the river discharge, and the waste disposal.

"The estuary begins at about Chain Bridge and extends southeastward to the Chesapeake Bay at lat $38^{\circ}$. The estuary is several hundred feet in width at the head and broadens in its length of 117 miles to nearly 6 miles at its mouth. A channel with a minimum depth of 24 feet is maintained in the estuary as far upstream as the upper end of the Washington Channel on the west side of Potomac Park in Washington. Except for the channel and depths of 80 feet at Chain Bridge and at The Three Sisters Islands, the estuary is relatively shallow; depths are predominantly less than 5 feet throughout most of the estuarine reach." 


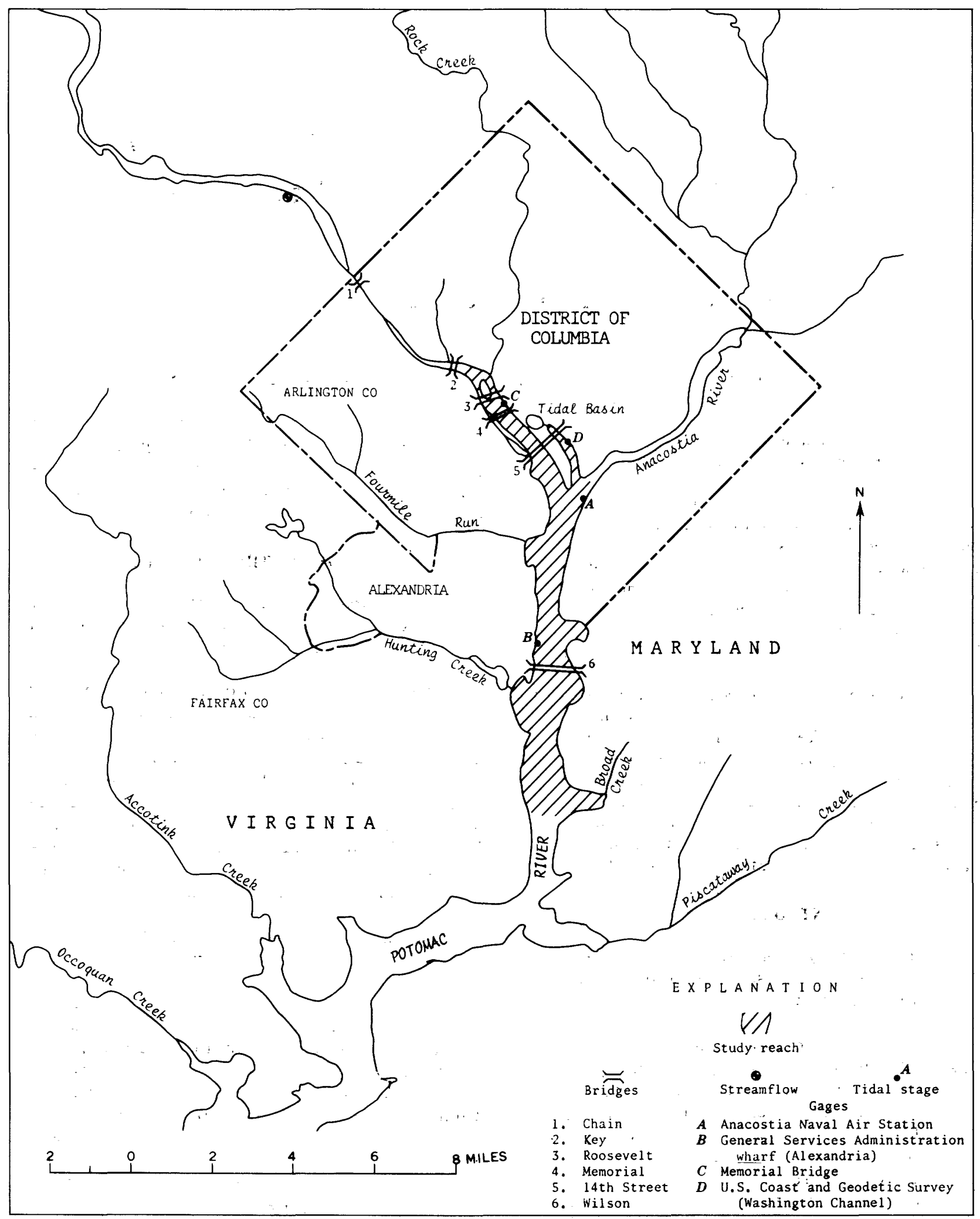

Figure 1. -Location of study reach. 
The study reach, shown in figure 1 , included that part of the reach described above which lies between Key Bridge ( 3.3 miles below Chain Bridge) and Broad Creek ( 3.5 miles below Woodrow Wilson Memorial Bridge).

\section{FIELD PROCEDURES}

On August 3, 1965, at 0700 e.s.t., 200 pounds of rhodamine $\mathrm{B}$ dye ( 30 percent solution) was injected into the Potomac River estuary at midstream, 1,000 feet upstream from the 14th Street Bridge in Washington, D.C. The dye was released during slack tide.

Shortly after the dye was released sampling was started. Dye concentrations were monitored continuously by use of a flow-through setup on the Turner Model 111 fluorometer mounted in a 17-foot boat. (See fig. 2.) The river water was pumped from the intake, located about 1 foot below the water surface, through the fluorometer by a $\frac{1}{2}$-horsepower pump, and fluorometer readings were recorded on a continuous strip chart. Periodic

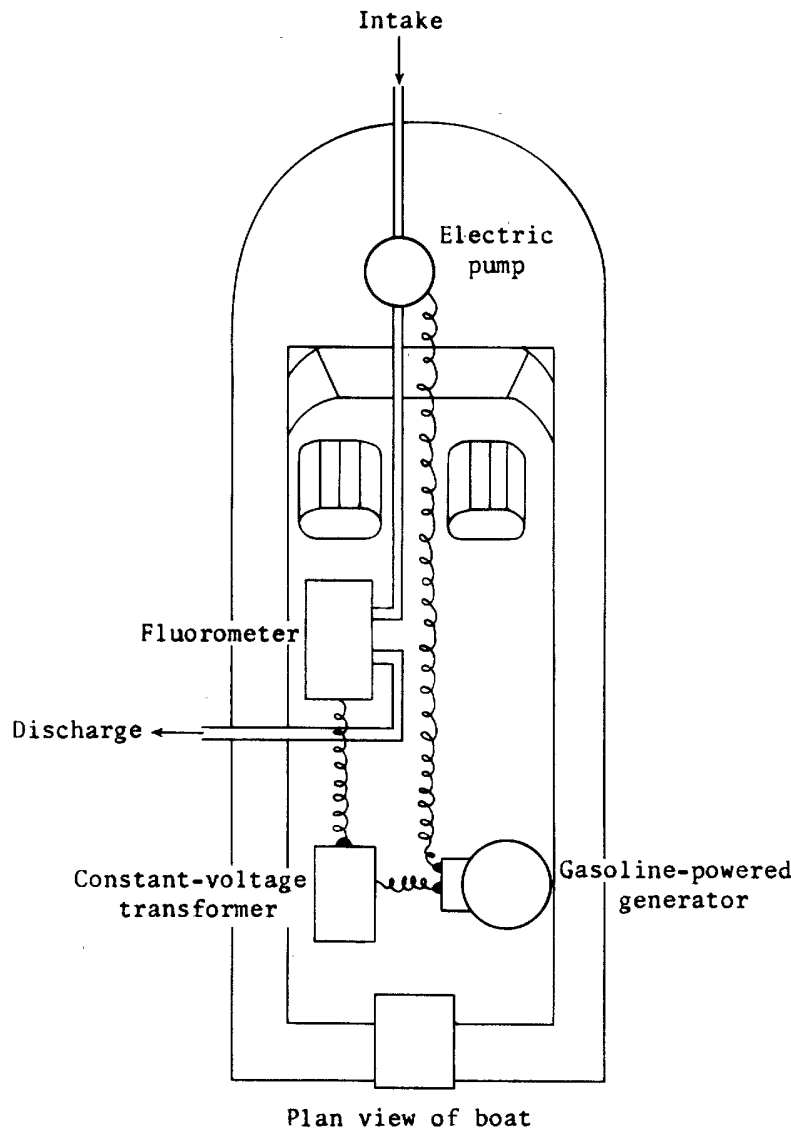

Figure 2.-Diagrammatic sketch of fluorometer hookup in sampling boat. grab samples were obtained along with the continuous monitoring to provide a means of calibrating the chart record. Water temperatures were recorded periodically to determine corrections to the fluorometer readings.

The above sampling system was used throughout the test period with the exception of one afternoon on August 6, when the fluorometer was temporarily out of service due to a broken cuvette. A set of grab samples was collected in lieu of the flow-through data during this period.

The location of the boat at any time was determined by the use of a Doppler navigator which was mounted on the bow of the boat. The navigator measured the distance that the boat had traveled from a selected location by sensing the Doppler effect of sound waves reflected off the streambed. Supplemental observations of buoys, bridges, and other welldefined landmarks were recorded and used to check the navigator.

A total of seven sets of surface-sampling data were collected in the study. Each set of data consisted of traverses along several cross sections and at least one traverse along a longitudinal axis of the channel. Each set of surface samples required successively longer sampling periods owing to the ever-lengthening dye cloud. Sampling periods varied from 30 minutes for the first set of data to 4.5 hours for the last set. Each set represents an average spatial distribution of concentration at the middle of the sampling period. Each sampling period was timed near a slack tide so that the extreme positions taken by the dye mass could be determined. The dye was traced until 1230 e.s.t., August 9 .

\section{PRESENTATION OF DATA}

\section{DYE-DISTRIBUTION MAPS}

The observed patterns of dye distribution are illustrated in the seven maps shown in chronological order, plate 1. Lines of equal concentration were drawn by observing the concentrations along a set of traverse lines and by assuming that the variation of concentration was uniform and continuous in the areas not sampled.

A bypass flow through the Tidal Basin and the Washington Channel is worthy of special mention. The movement of dye into this 
4 MOVEMENT OF A SOLUTE IN THE POTOMAC RIVER ESTUẢ RY AT WASHINGTON, D. C., AT LOW INFLOW CONDITIONS

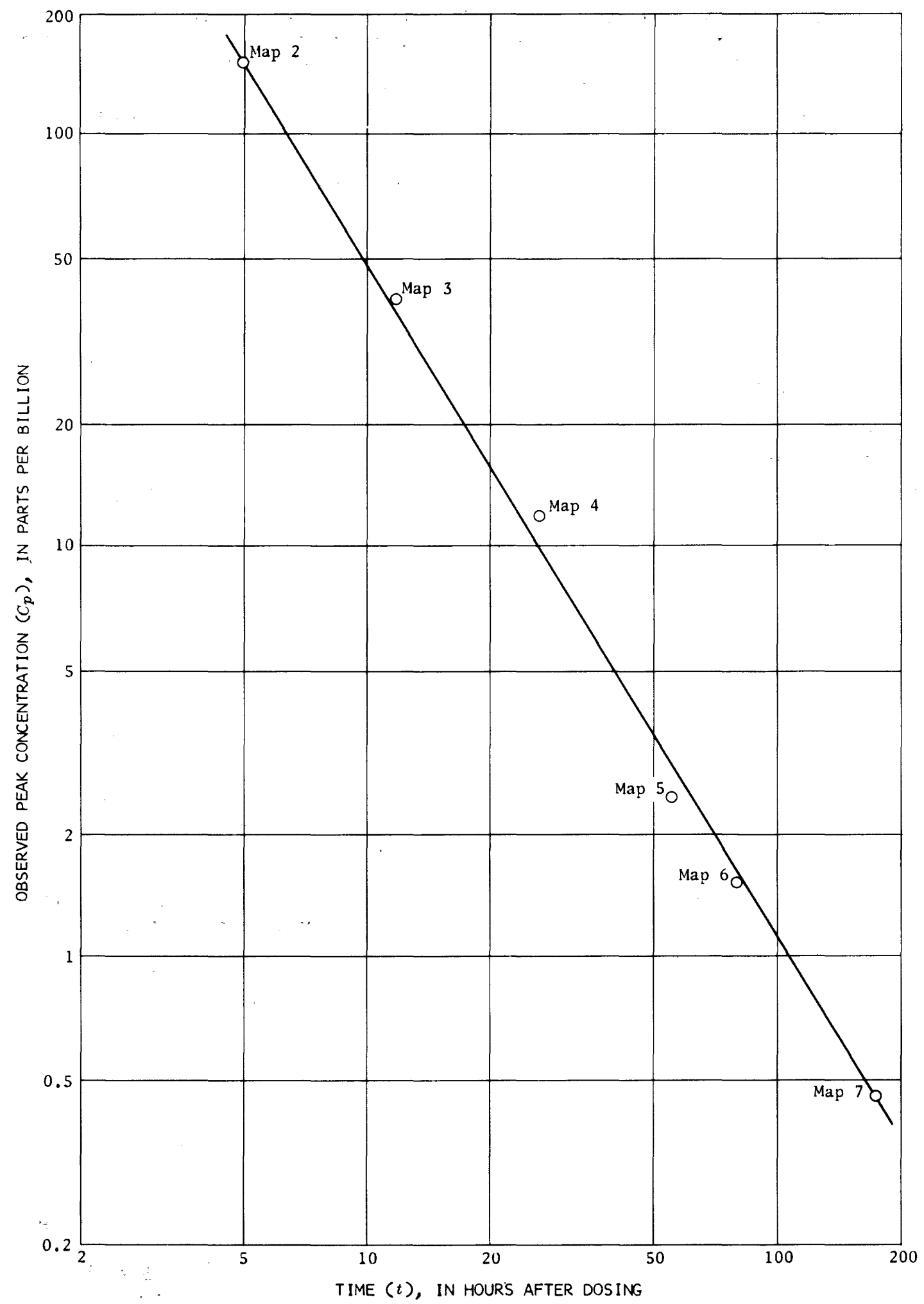

1. Map number refers to map on plate 1 .

2. Values of $C p$ are not adjusted for dye loss.

Figure 3.-Attenuation of peak concentration with time. 


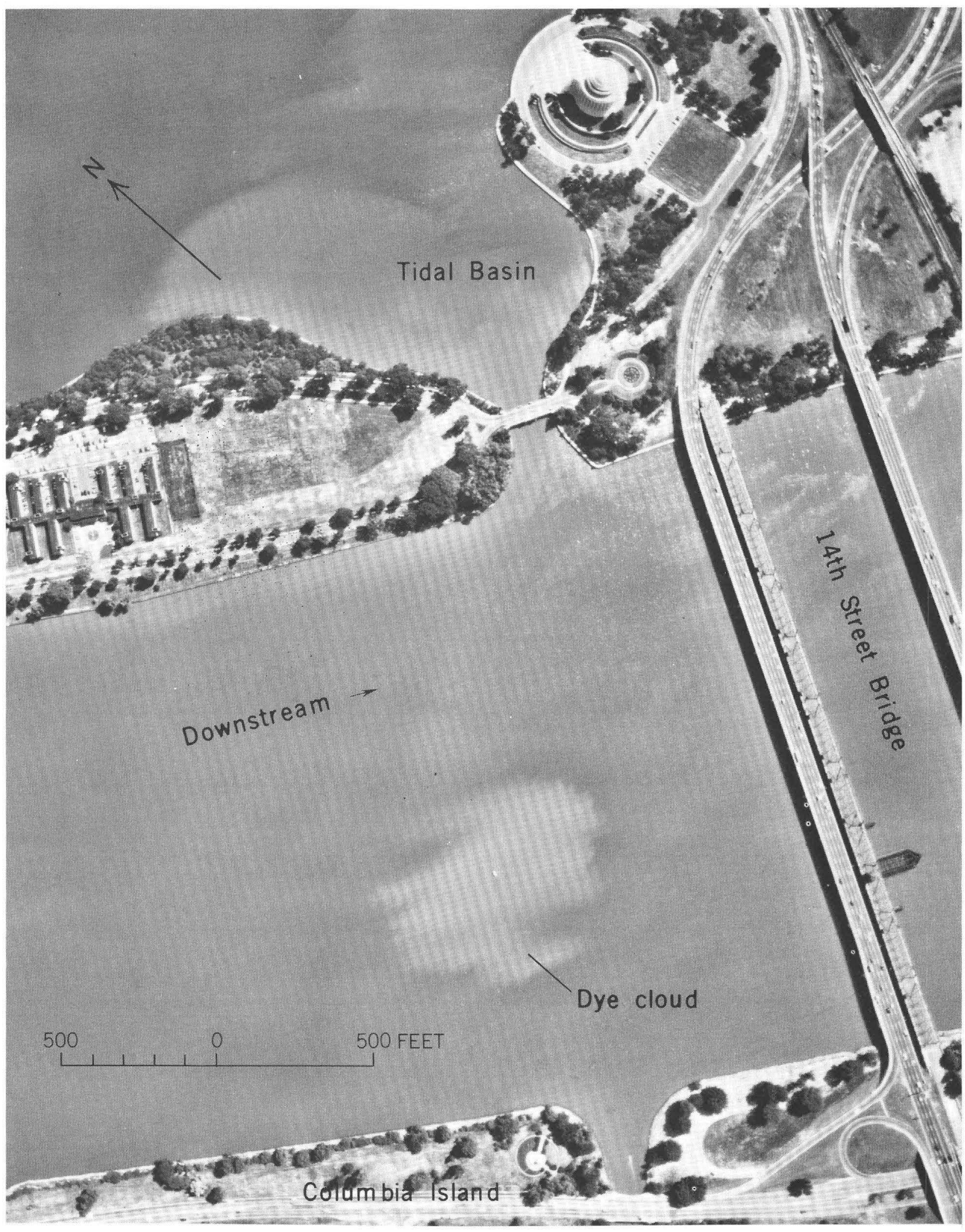

Figure 4.-Aerial photograph of dye cloud 1.9 hours after dye injection. 
6 MOVEMENT OF A SOLUTE IN THE POTOMAC RIVER ESTUARY AT WASHINGTON, D. C., AT LOW INFLOW CONDITIONS
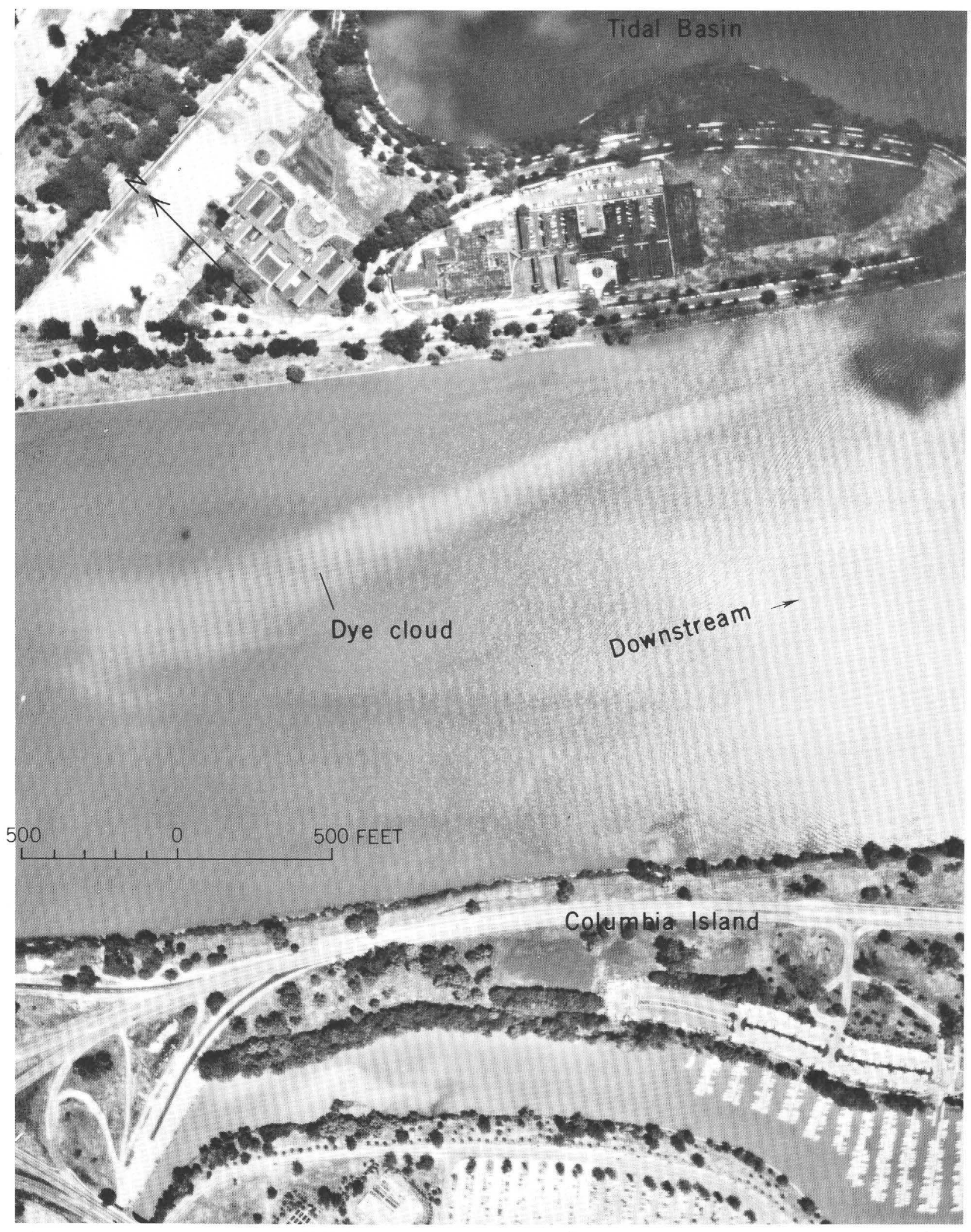

Figure 5. - Aerial photograph of dye cloud 4.4 hours after dye injection. 


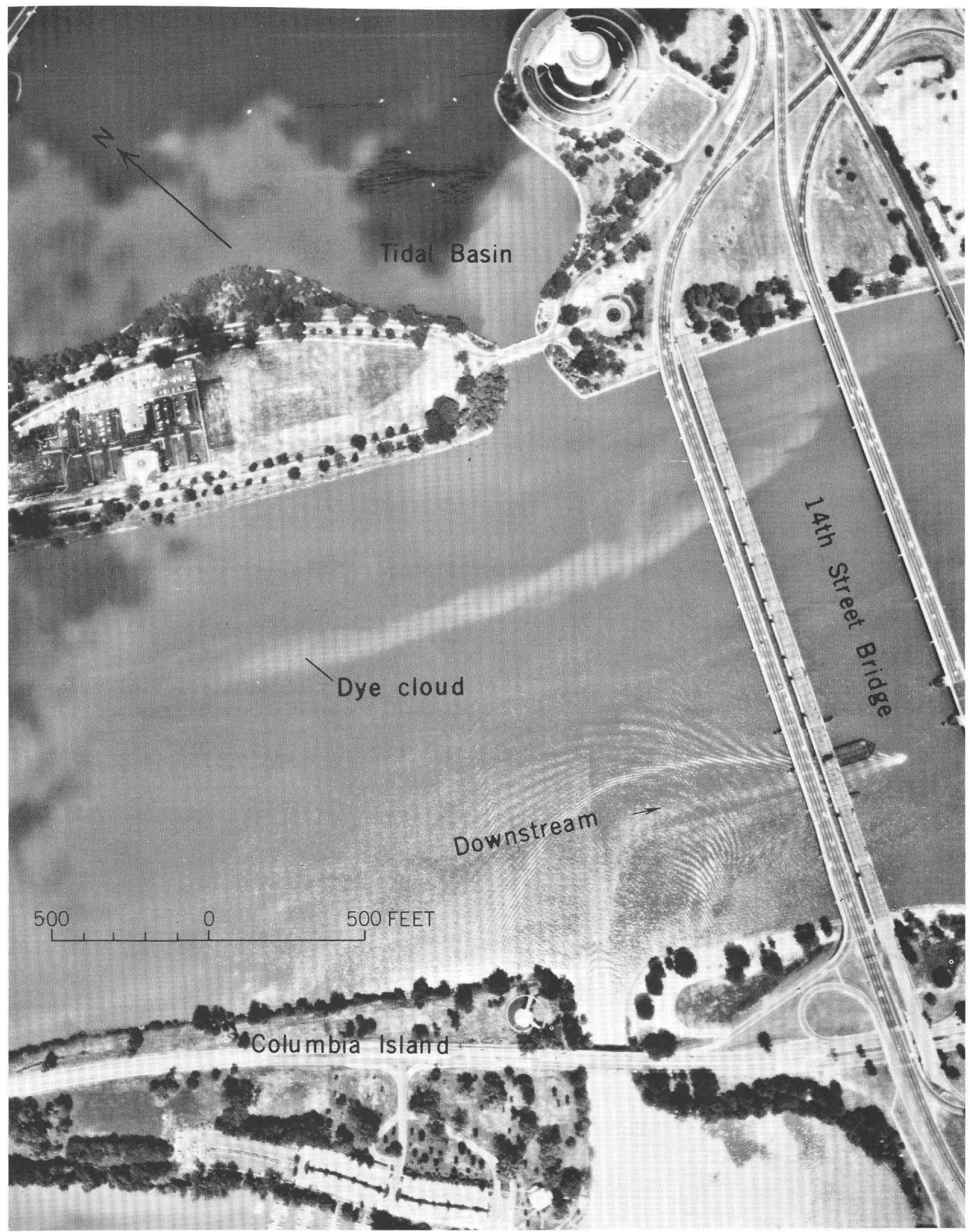

Figure 6.-Aerial photograph of dye cloud 6.7 hours after dye injection. 
channel was visually noticeable during the first ebb tide, and the exchange between the main channel and the bypass must have continued for a number of subsequent tidal periods. Other than by aerial photographs, the movement of this portion of the dye was not monitored until the last day and was excluded from the computations. According to the mass recovery computations for the main channel, this bypass dye was relatively small in quantity. On the other hand, the isolated dye itself remained relatively undispersed for a considerable period of time apparently because of low flow velocities in the bypass channel, map 7, plate 1 .

A plot of the observed peak dye concentration, $C_{p}$, from the dye-distribution maps against elapsed time is shown in figure 3 . The points line up well on a straight line which has a slope of -1.6. The attenuation of peak concentration with time is indicative of the combined effect of the dilution capacity of the estuary and the dye loss; therefore, the slope of the relationship should not be construed as a constant characteristic of this estuary.

\section{AERIAL PHOTOGRAPHS}

A number of aerial photographs of the dye cloud, both in color and in black and white, were taken during the early stages of the experiment. Although quantitative evaluation of the photographs is outside the scope of this report, three selected examples are shown in figures 4-6. The white images of the dye cloud against darker water are the result of using an orange sharp-cut filter on the camera with ordinary black and white film.

Photographs are limited, of course, to periods of daylight and to the time span during which the dye cloud is visible; in the present study the dye cloud was only visible on the first day. The obvious general value of aerial photographs is that they provide instantaneous synoptic views of the dye cloud and reveal fine structure of the cloud not shown by surface sampling. The general shapes of the dye cloud determined by surface sampling in maps 1 and 2, plate 1, compare favorably with the shapes revealed in the three photographs, figures 4-6.

\section{STAGE AND DISCHARGE RECORDS}

Records of stage were obtained at the GSA (General Services Administration) wharf in Alexandria, Va., and at the Anacostia Naval Air Station. (See fig. 1.) The difference in watersurface elevations between the two gages was always less than 0.2 foot, and the time lag between peak stages at these two gages was about 10 minutes. The record of stage variation obtained at the GSA wharf is shown in figure 7.

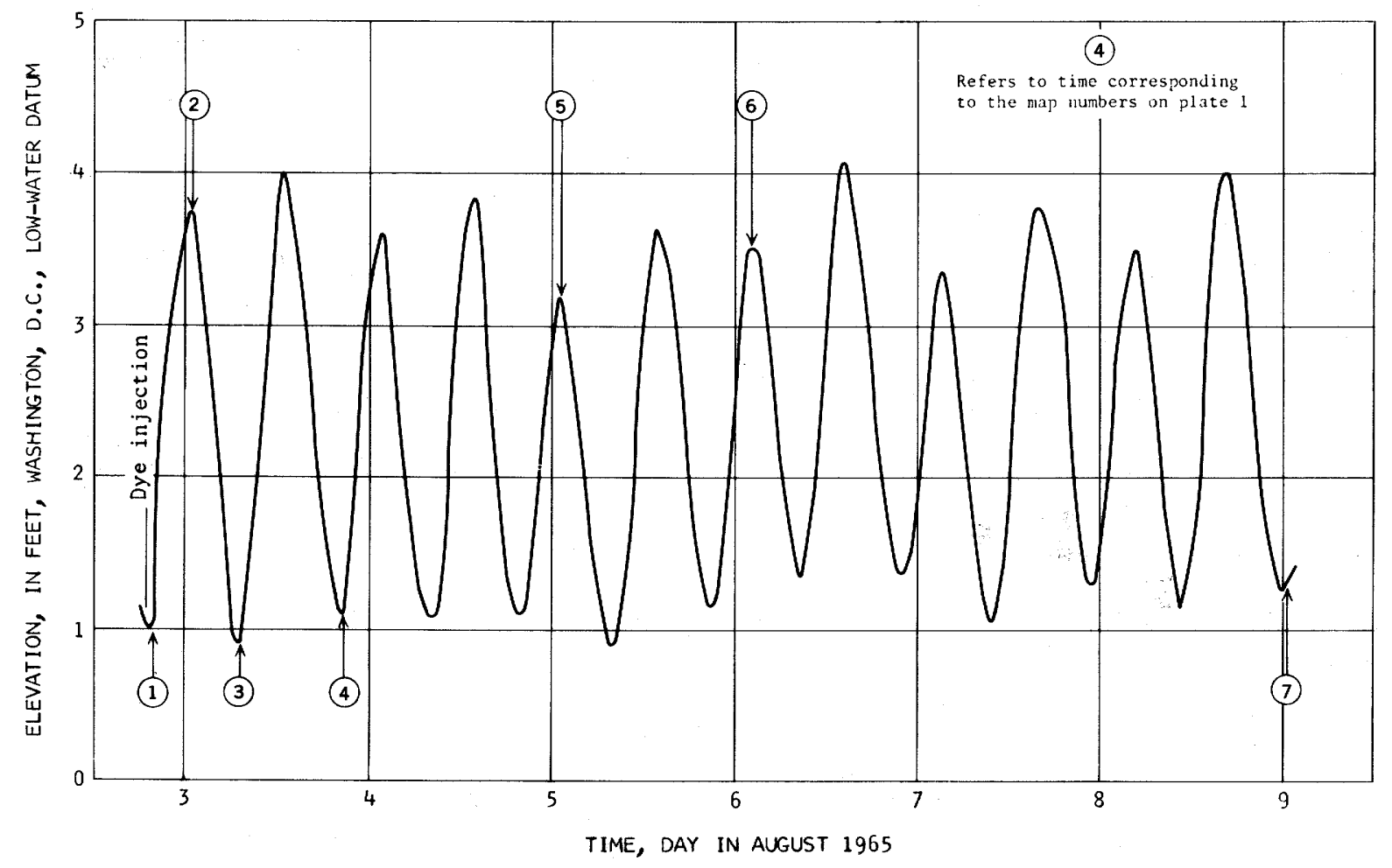

Figure 7. - Potomac River estuary water-surface elevations at GSA wharf, Alexandria, Va. 


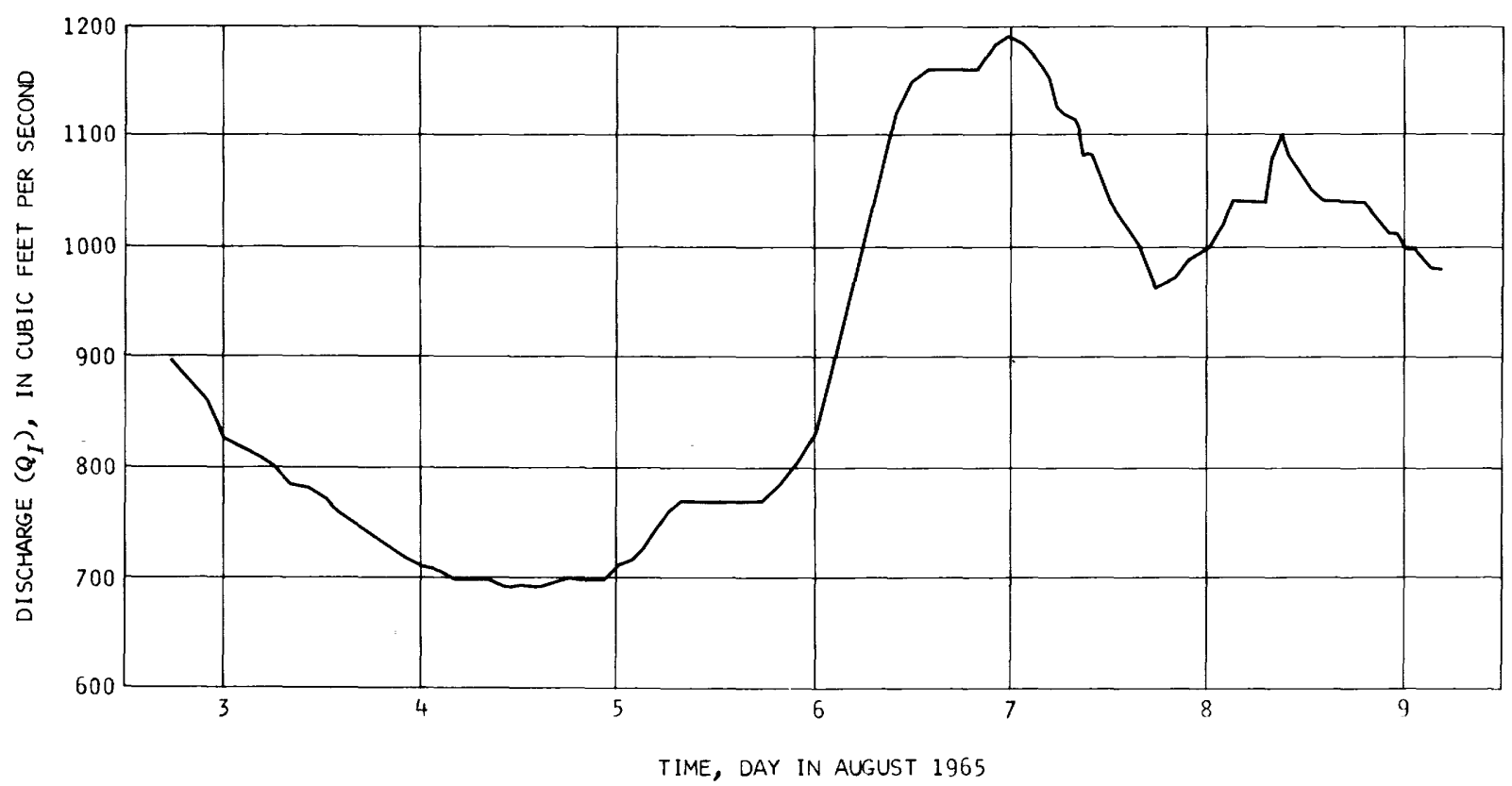

Figure 8. -Nontidal discharge flowing into the Potomac River estuary. Hydrograph is for the gaging station, Potomac River near Washington, D.C., 2 1/4 miles upstream from Chain Bridge.

Nontidal discharge in the Potomac River above Chain Bridge, together with minor discharges from Rock Creek, Fourmile Run, and the Anacostia River, constitute the net inflow to the estuary. The discharge hydrograph for the gage, Potomac River near Washington, D.C., is shown in figure 8.

\section{AVERAGE MOVEMENT OF DYE MASS}

\section{OBSERVED MOVEMENT}

Time of travel in an upland stream without tidal action usually is defined as the time taken by the centroid of a dye mass to travel from one specified point to another downstream point in a reach, the centroid representing an average location for all dye particles. In an estuary, however, such time of travel is not so defined, because a dye mass subjected to tidal action may pass specified points several times. Accordingly, "average movement of dye" refers to distance traveled instead of time. The measurement of the dye-mass centroid is most meaningful if it is measured at both slack periods of tidal cycles so that a series of extreme upstream and downstream positions of the dye mass can be defined along the river axis. In this study, mass centroids from dye-distribution maps 1, 3, 4, and 7, plate 1, represent the approximate extremes at the end of ebb tides, whereas those from maps 2, 5, and 6 represent the approximate extremes at the ends of flood tides.
The following procedure was used to compute the location of the dye-mass centroids:

1. On a given map, 10 to 20 cross sections were marked off to sufficiently define the distribution of the dye. The intervals between cross sections were not necessarily uniform, because of the shapes of the concentration isolines. The cross sections were assigned numbers, $i=1,2, \ldots, N$ ( $N$ is the total number of cross sections). Areas or concentrations to the east of a line between Hains Point and Giesboro Point were not included in cross sections located at the mouth of the Anacostia River. Similar deletions were made for the larger bays, such as the mouth of Hunting Creek.

2. For each cross section, $i$, observed dye concentrations (assumed to be uniform vertically) and water depths were plotted against width. The cross section was then divided into about 20 subsections of uniform width.

3. For each subsection, the product of subwidth, depth, and average dye concentration was determined. The sum of these products, $M_{i}$. represents the total mass of dye per unit length of subreach associated with the $i$ th cross section. The distribution of the dye mass along the estuary is shown in figure 9. It is noted that the ordinate $M_{i}{ }^{\prime}$ is obtained by uniformly adjusting $M_{i}$ for the measured dye loss, so that the area under the curve remains the same for all maps. 

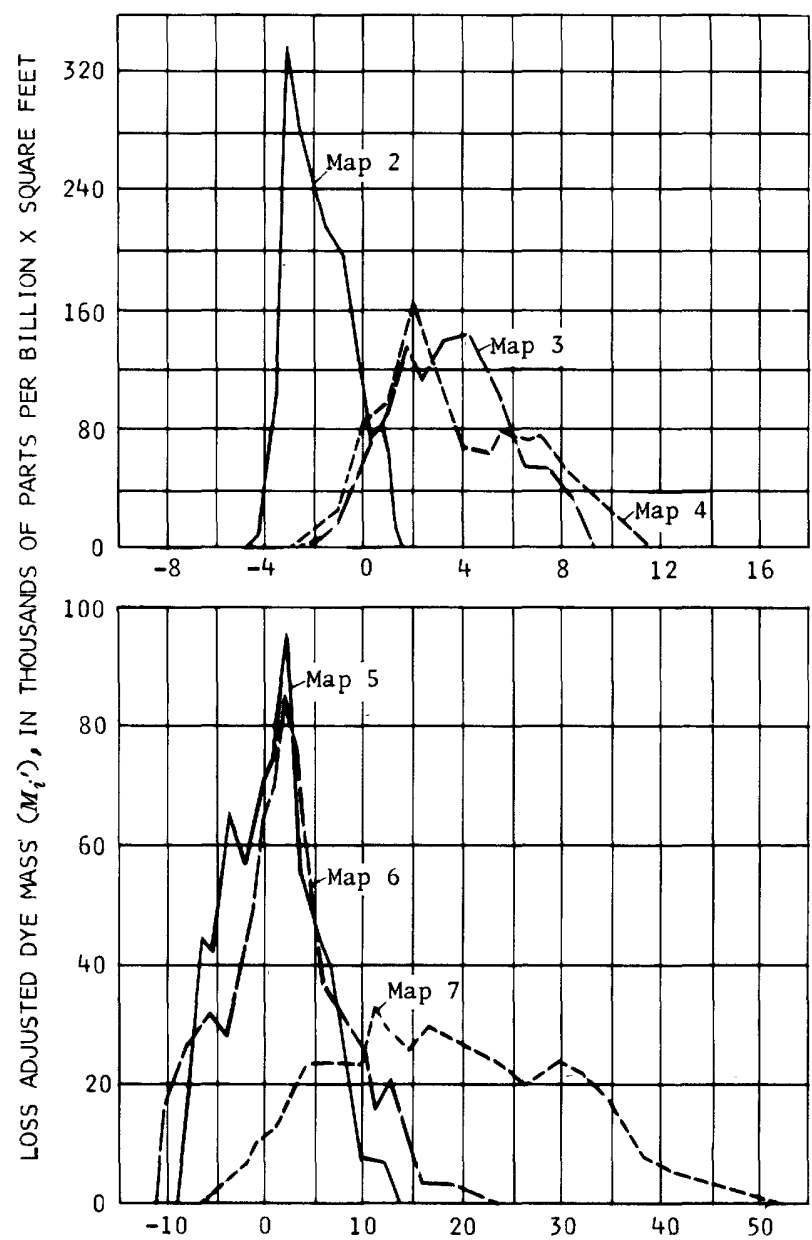

RIVER DISTANCE $\left(X_{i}\right)$, IN THOUSANDS OF FEET FROM DYE-INJECTION SITE

Map number refers to map on plate 1

Figure 9. -Distribution of dye mass in the longitudinal direction.

4. For each cross section, $i, M_{i}$ was multiplied by the subreach length, $\Delta X_{i}$, associated with that cross section, where $\Delta X_{i}$ is equal to one-half the distance between the two adjacent cross sections, $i+1$ and $i-1$. The sum of the products represents the total mass of dye observed for this sampling period.

5. The dye-mass centroid location, $\bar{X}$, was computed as the first moment of the distribution of $M_{i}$ in the longitudinal direction. The moment arm, $X_{i}$, was the estuary centerline distance from the dye-injection site. Values for $X_{i}$ were designated as positive in the downstream, or seaward, direction and negative in the upstream direction. In equation form, the dye-mass centroid is defined as

$$
\bar{X}=\frac{\underset{\substack{i=1 \\ N}}{N} \Delta X_{i} X_{i}}{\sum_{i=1}^{N M_{i} \Delta X_{i}}}
$$

The mass-centroid positions for maps 2-7 (p1. 1) are plotted in figure 10. It may be seen that by the end of an ebb tide on August 9 the centroid had traveled a net downstream distance of 19,400 feet, or 3.7 miles. Considering the period between the time of release, 0700 e.s.t., August 3, and the end of measurement, 1230 e.s.t., August 9, the average velocity of net downstream motion is less than 0.6 mile per day-a very slow movement in comparison with that in most upland streams. Also apparent is the fact that the mass centroids measured at the end of ebb tides and flood tides form two separate envelopes within which the to-and-fro motion of the dye-mass centroid is restricted.

\section{ESTIMATED MOVEMENT}

The average movement of the centroid of a solute in the estuary was estimated using the following equation of continuity,

$$
Q_{O}=Q_{\Gamma}-\Delta S / \Delta t
$$

where

$Q_{O}$ is the flow through a cross section,

$Q_{I}$ is the total nontidal inflow to the estuary, and

$\Delta S$ is the change of storage upstream from the cross section during the time increment, $\Delta t$.

$Q_{I}$ is always positive, whereas $\Delta S$ is defined as positive if the stage is rising with time and negative if it is falling with time. $Q_{O}$ is positive if the flow is downstream and negative if the flow is upstream.

Two other equations required to estimate the water movement are

$$
V=Q_{O} / A
$$

and

$$
\Delta X=V \Delta t
$$




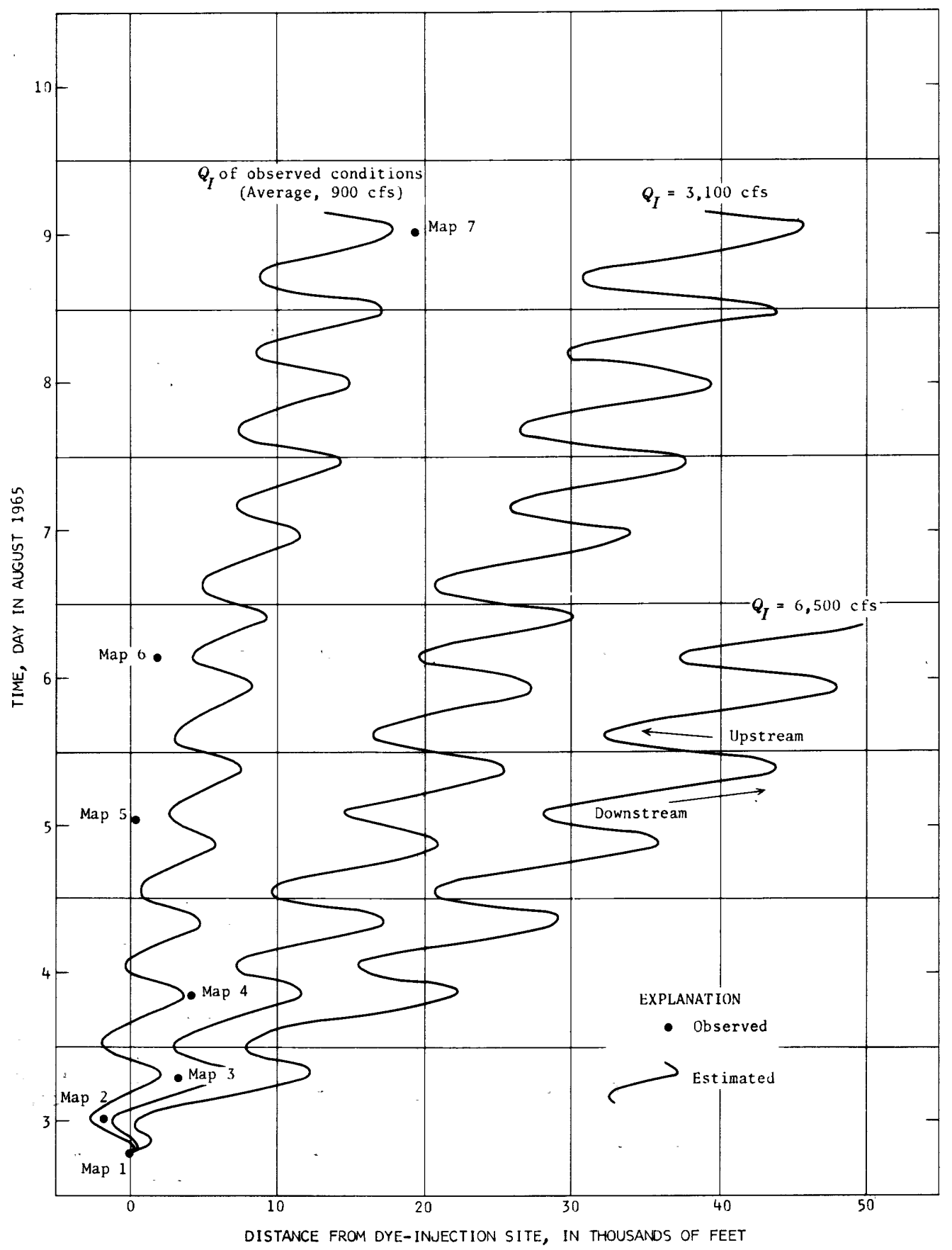

Map number refers to map on plate 1

Figure 10--Observed and estimated movement of dye-mass centroid with time.

where

$V$ is the average tidal velocity,

$A$ is the cross-sectional area of flow, and

$\Delta X$ is the distance of travel during the time interval, $\Delta t$.
The signs of $V$ and $\triangle X$ are the same as $Q_{O}$; that is, they are positive if the flow is downstream and negative if the flow is upstream.

Most of the inflow $Q_{I}$ came from the nontidal Potomac River discharge. A small adjustment was made to include minor discharges from other streams. For the study period, $Q_{I}$ ranged 
from 700 to $1,200 \mathrm{cfs}$, averaging approximately $900 \mathrm{cfs}$ (cubic feet per second). (See fig. 8.) This is considered to be very low flow, being equaled or exceeded 98 percent of the time during the 28-year period, 1931 through 1958 .

The change in storage, $\Delta S$, was determined from the surface area of water in the estuary and from the change in stage. The surface area was determined from U.S. Geological Survey topographic maps. It was assumed that this area did not change significantly in the range of stage normally resulting from tides. The change of stage was determined from the stage record obtained at the Anacostia Naval Air Station. The water surface for the area under study was assumed to rise and fall as a horizontal plane. No corrections were made for the small slope in the water surface.

A time increment, $\Delta t$, of 15 minutes was used in the computations. The starting cross section was at the dye-injection site, and $Q_{O}$ at that section was computed from equation 2 for the first 15-minute period. The average tidal velocity, $V$, and distance of travel, $\Delta X$, during the first 15-minute period were computed from equations 3 and 4 , respectively. The second cross section was then located at a distance of $\Delta X$, computed from equation 4 , from the initial location, and $Q_{O}, V$, and $\Delta X$ were computed in similar fashion for the second 15minute increment. The procedure was repeated for successive 15-minute time increments for the total time period of interest-approximately $6 \frac{1}{2}$ days.

Results of the computations are plotted in figure 10 to compare with the observed movement of the dye. The agreement is generally satisfactory. The fact that most of the observed points lie outside of the estimated curve suggests that the dye cloud was traveling faster than the average water particles, probably because of the lack of complete lateral mixing throughout the entire sampling period.

The results of the first set of computations were encouraging enough that the computations were extended to two hypothetical cases, also shown in figure 10. Values of $Q_{I}$ of 3,100 and 6,500 cfs were used in these computations. The discharges of 3,100 and $6,500 \mathrm{cfs}$ at the Potomac River gage upstream from Chain Bridge are expected to be equaled or exceeded, respectively 75 and 50 percent of the time. According to past records, the range of stage variation in the estuary is nearly independent of $Q_{I}$ if $Q_{I}$ is less than $40,000 \mathrm{cfs}$. Therefore, the $\Delta S$ data used in the observed computations were assumed to be applicable for the two hypothetical cases. The computations indicate that the downstream movement is very closely related to $Q_{l}$; the rate of increase in the movement is slightly less than the rate of increase in $Q_{I}$ for the computed range.

\section{CHARACTERISTICS OF DISPERSION}

The seven dye-distribution maps, plate 1 , show a complex but steadily progressing pattern of dye dispersion in the study reach. Two general features are immediately noticeable. One is that even after 150 hours of diffusion, the cross-channel distribution of dye concentration was far from being uniform. The other feature is that the dye cloud stayed closer to the left bank than the right throughout the study. This appears to be a persisting effect of an early drifting of the dye. The dye mass, initially poured at the middle of the stream, remained almost stationary for about 2 hours after the release. During the ensuing period of the first flood tide, the dye mass was rapidly elongated between the 14th Street and Memorial Bridges. (See figs. 4 and 5.) At the same time, for some undetermined reason, the main part of the dye drifted toward the left bank.

The recovery of dye mass for each map of plate 1 , which was computed in step 4 (p. 10) of the centroid determination, is tabulated in table 1 . The values given in table 1 for maps

Table 1.-Computed recovery of the total dye mass at various stages of dilution

\begin{tabular}{|c|c|}
\hline $\begin{array}{c}\text { Map No. } \\
\text { (pl. 1) }\end{array}$ & $\begin{array}{l}\text { Computed } \\
\text { recovery } \\
\text { (percent) }\end{array}$ \\
\hline 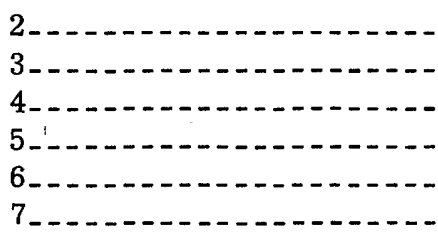 & $\begin{array}{r}105 \\
138 \\
121 \\
68 \\
47 \\
32\end{array}$ \\
\hline
\end{tabular}

numbered 2-4 ( $\mathrm{pl} .1$ ) reflect the inadequacy of the dye-cloud sampling in the early stages of the study.

From the viewpoint of considering movement of dissolved substances introduced as a point source, the progress of the longitudinal dispersion is probably the most important because 

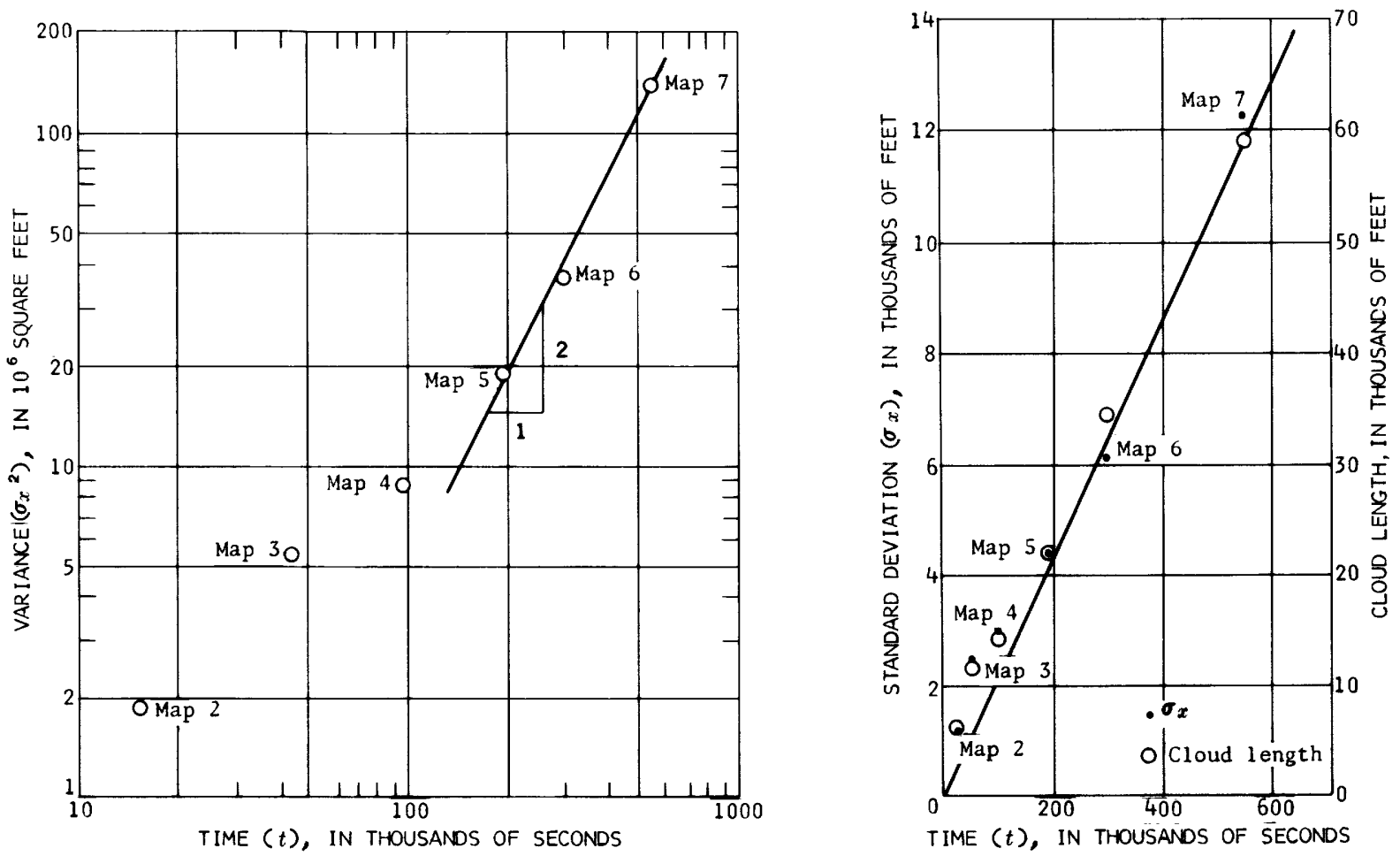

Map number refers to map on plate 1 .

Figure 11. - Increase of variance and length of dye cloud with time.

of its predominant role in the total dilution. As a primary measure of this dispersion, the longitudinal length of the dye cloud may be plotted against time. A more stable parameter, however, is the variances of the longitudinal mass distribution. The variance, $g_{x}^{2}$, was computed by the formula

$$
\sigma_{x}^{2}=\frac{\sum_{i=1}^{N} M_{i}\left(\bar{X}-X_{i}\right)^{2} \Delta X_{i}}{\sum_{i=1}^{N} M_{i} \Delta X_{i}}
$$

A plot of $\sigma_{x}^{2}$ against time is presented in figure 11. At large dispersion times, $\sigma_{x}^{2}$ was increasing almost linearly with the square of time, $t$. Consequently, the longitudinal dispersion coefficient, defined as one-half of the rate of increase of $\sigma_{x}{ }^{2}$ with $t$, had not attained a constant value. A transient value of $210 \mathrm{sq} \mathrm{ft}$ per sec (square feet per second) was obtained by observing that the rate of increase of $\sigma_{x}^{2}$ with time between maps 6 and $7(\mathrm{pl}, 1)$ was about $420 \mathrm{sq} \mathrm{ft}$ per sec. In figure 11 , the longitudinal cloud length and the standard deviation, $\sigma_{x}$, are also plotted against time to demonstrate the consistent relation between the total length and $\sigma_{x}$.
The peak of the dye-mass distribution, $M_{p}{ }^{\prime}$, is plotted against time in figure 12. Again, the ordinate $M_{p}{ }^{\prime}$ is the adjusted value for dye loss (table 1) rather than the observed $M_{p}$. It may be seen that, at large dispersion times, $M_{p}^{\prime}$ 'is about inversely linear with time. This is to be expected from the principle of the

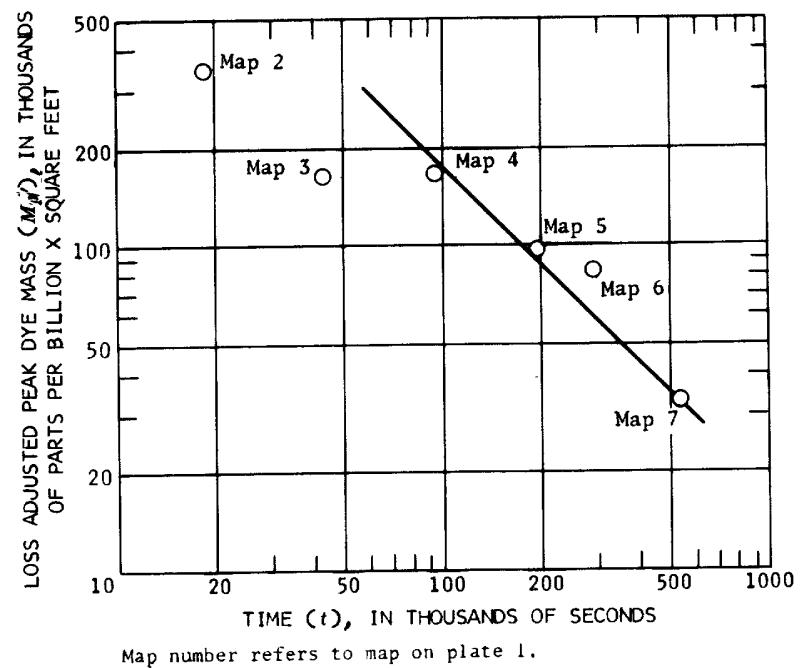

Figure 12. -Attenuation of peak dye mass with time. 
Table 2.--Product of peak dye mass, $\mathrm{M}_{\mathrm{p}}$, and dye cloud length, $\mathrm{L}$, at various stages of dilution

\begin{tabular}{c|c}
$\begin{array}{c}\text { Map No. } \\
\text { (pl. 1) }\end{array}$ & $\begin{array}{c}M_{p}{ }^{\prime} \cdot L \text { in } \\
\mathrm{ppb} \times \mathrm{cu} \mathrm{ft}\end{array}$ \\
\hline & 2,102 \\
\hline & 1,966 \\
& 2,453 \\
& 2,153 \\
\hline
\end{tabular}

continuity of dye mass which may be crudely expressed by the constancy of the product of the cloud length and $M_{p}{ }^{\prime}$ (table 2). If the cloud length of $\sigma_{x}$ varies linearly with time, $M_{p}{ }^{\prime}$ should be inversely linear with time.

The above dispersion parameters are not applicable for the prediction of dispersion at other flow conditions in this estuary because a correlation of the dispersion parameters with the hydraulic variables is not available from just one test.

\section{SUMMARY AND CONCLUSIONS}

The surface-sampling data and its analysis produced useful information on the movement of a solute in the upper end of the Potomac River estuary at Washington, D.C. Quantitative analysis of the rate of movement and the dispersion characteristics was based on the distribution of dye mass rather than dye concentration. The analysis was reduced to a onedimensional approach. However, this should not obscure the fact that the dye movement in the estuary was essentially a two-dimensional phenomenon throughout the study period.

Several conclusions derived from the study are itemized as follows:

1. The centroid of the dye mass injected near the 14th Street Bridge traveled downstream at a net daily rate of less than 0.6 mile for the 6-day period. Nontidal discharge at Chain Bridge varied from 700 to $1,200 \mathrm{cfs}$ in this period, averaging $900 \mathrm{cfs}$.
2. The above rate of net movement, defined daily at a fixed phase of the tidal cycle, is primarily controlled by the nontidal discharge flowing into the estuary. However, during each tidal cycle, the centroid of a solute mass moves approximately with the average tidal velocity of water, which changes direction approximately every 6 hours.

3. Tidal actions are fairly efficient means of diluting the dye in the longitudinal direction; the rate of increase of the longitudinal variance was almost proportional to the square of elapsed time. A transient longitudinal dispersion coefficient at the end of 150 hours was $210 \mathrm{sq} \mathrm{ft}$ per sec. However, the lateral diffusion was far from complete even after the $6 \frac{1}{2}$-day test period.

4. At low inflow to the estuary, the dye disperses upstream to a point where the inflow to the estuary is sufficient to prevent further upstream movement; in this study no dye was observed above Key Bridge. As the inflow to the estuary increases, the upstream distance which the dye would be expected to move would decrease. Of importance is that a contaminant dumped at a downstream point can move some distance upstream and pollute upstream as well as downstream areas. Increased inflow to the estuary would be expected to decrease this effect.

\section{REFERENCES}

Durum, W. H., and Langbein,W. B., 1966, Water quality of the Potomac River estuary at Washington, D.C.: U.S. Geol. Survey Circ. 529-A, 9 p.

Hetling, L. J., and O'Connell, R. L., 1966, A study of tidal dispersion in the Potomac River: Water Resources Research, v. 2, no. 4 , p. 825-841.

Wilson, J. F., and Forrest, W. E., 1965, Potomac River time-of-travel measurements: Lamont Geol. Observatory Symposium on Diffusion in Oceans and Fresh Waters, Palisades, N. Y., 1964, Proc., p. 1-18. 